\title{
Assessing Physician Awareness of the Choosing Wisely Canada Recommendations
}

Seth J. Stern MSc MD, Anne Holbrook MD, PharmD, MSc, FRCPC, Matthew Patel, Christopher Hillis MD MSc, Ameen Patel MB FRCPC

\begin{abstract}
About the Authors
Seth J. Stern, PGY-4 General Internal Medicine, at McMaster University, Hamilton, ON. Anne Holbrook, is director, Clinical Pharmacology \& Toxicology Department of Medicine at McMaster University, Hamilton, ON. Matthew Patel is with the Royal College of Surgeons in Ireland. Christopher Hillis is with the Department of Oncology at McMaster University, Hamilton, ON. Ameen Patel is with the Department of Medicine, Division of GIM, at McMaster University, Hamilton, ON.
\end{abstract}

Correspondence may be directed to seth.stern@medportal.ca

Submitted: March 26, 2017. Accepted: September 26, 2017. November 7, 2017.

\begin{abstract}
Background: Choosing Wisely Canada (CWC), an initiative to reduce low-value care, launched in April 2014. However, it remains unclear to what extent physicians are aware of the initiative and specific recommendations. The objective of this study was to assess physician awareness of the CWC campaign and recommendations, in addition to assessment of attitudes and perspectives on low-value medical care.

Methods: This study was conducted as a survey of faculty physicians and residents of McMaster University. Electronic surveys were sent to all faculty physicians and residents within specialties with CWC recommendations. Responses were analyzed to determine awareness of CWC recommendations, defined as awareness of $\geq 3$ recommendations targeted to a respondent's respective specialty.

Results: A total of 361 respondents were included in the analysis (response rate $=33 \%$ ). Eighty-eight percent of respondents were aware of the CWC campaign. Only 30.1\% (95\% CI 23.5-36.7\%) of respondents were able to correctly describe $\geq 3$ of the recommendations targeted to their respective specialty, with a mean of 1.6 (95\% CI 1.4-1.9) recommendations correctly identified per respondent. Most recommendations (70.9\%) were reported as already being part of a respondents' practice prior to release of the CWC recommendations.

Interpretation: Despite general awareness of the CWC campaign, more than two thirds of physicians cannot describe most recommendations targeted to their own specialty. Nonetheless, many of these physicians report already practicing in compliance with these recommendations. Future studies are required to identify methods to improve communication, to track compliance with current CWC recommendations, and to determine areas of care that would most benefit from additional recommendations.
\end{abstract}

Choosing Wisely Canada (CWC), an initiative to reduce lowvalue and unnecessary medical care, launched in April 2014. ${ }^{1}$ Modeled after the Choosing Wisely campaign in the US, ${ }^{2} \mathrm{CWC}$ seeks to engage clinicians and patients in conversation about unnecessary tests and treatments. The campaign centres on "top five" lists developed by medical specialty societies of items within their respective specialties deemed to be of low-value, lacking benefit, or potentially harmful. ${ }^{3} \mathrm{CWC}$ recommendation lists were intended to be physician-led, patient-focused, evidencebased, multi-professional, and transparent, ${ }^{4}$ with each group formulating their own list using these guiding principles. 
The Institute of Medicine estimates that approximately $30 \%$ of health care in the US adds no value to patient care. ${ }^{5}$ Additionally, a large majority of physicians have recognized over-testing as an issue, and $72 \%$ of those surveyed acknowledge ordering at least one unnecessary test or treatment each week. ${ }^{6}$ Common reasons cited for doing so included concerns for malpractice, safety, and patient preference.

Specific list recommendations have been rolled out by national specialty societies and in local campaigns in hospitals across Canada. Further, Canadian medical schools are beginning to incorporate the campaign into the undergraduate curriculum through the Students and Trainees Advocating for Resource Stewardship campaign, and resource stewardship has been added to the CanMEDS 'Leader' competency. ${ }^{7,8}$ However, early research out of the US suggests that its now 3-year-old campaign has had variable success, with little effect on national physician practice. Analysis of 7 low-value services found only a very modest improvement in practice in two specific Choosing Wisely recommendations. ${ }^{9}$ Of the remaining five, three demonstrated no change in practice, and two revealed changes contradictory to the recommendation.

As the campaign has passed the 3-year mark in Canada, it is not yet known what effect it has had on physician practice. Furthermore, it remains unclear to what extent physicians, including trainees, have been aware of the initiative, and whether they are aware of specific recommendations relevant to their own specialty. The objective of this study was to assess physician awareness of the CWC campaign, both in terms of general awareness and of specialty-specific recommendations, in addition to assessment of attitudes and perspectives on lowvalue medical care.

\section{Methods}

\section{Design and Population}

The study was conducted as a survey among physician residents and faculty at McMaster University in Hamilton, Ontario. The project was exempted from full review by the Hamilton Integrated Research Ethics Board.

The survey was sent to all residents and faculty within specialties that had existing CWC recommendations at the time of survey dissemination. Email lists of residents and faculty physicians were provided to us from individual programs. Emails were initially sent in March 2016, with reminder emails sent out monthly for two subsequent months. The survey remained open from March to June 2016. Respondents were excluded from survey analysis if their primary specialty lacked CWC recommendations, or if they self-reported that less than $10 \%$ of their work was devoted to clinical duties.

\section{Content}

The survey questions were created to collect data on respondent demographics, awareness of CWC recommendations, and to assess attitudes and perspectives of respondents on low-value medical care. Questions were devised via discussion among content experts, and in conjunction with previously unpublished surveys that assessed similar themes. After initial completion, the survey was pilot tested among ten residents and faculty physicians, and subsequent changes were made to improve on its readability, avoid misinterpretation of specific questions, and improve response options.

The primary outcome of the survey was the proportion of respondents with awareness of at least three of the CWC recommendations targeted to their respective specialty. If a respondent answered positively to awareness of the CWC campaign, they were asked to describe up to five of the recommendations in their own words, including for each recommendation the (1) target population, (2) test, procedure, and/or intervention, and (3) clinical context (when applicable). Responses were categorized as correctly aware of the recommendation if they included all of (1), (2), and (3, when applicable). Two independent adjudicators assessed responses; if disagreement occurred following a consensus step, the response was assessed by a third adjudicator.

\section{Data Analysis}

Survey data was analyzed using descriptive statistics. Primary outcome data is presented using confidence interval on a proportion.

\section{Results}

\section{Demographics}

The survey was sent to 1361 physicians, with 446 individuals (201 faculty physicians, 245 residents) responding to the survey (response rate $=33 \%$ ). Of these, 85 were excluded for various reasons ( 47 for incomplete surveys, 26 for primary specialty without CWC recommendations, and 12 for self-reporting less than $10 \%$ of their work as devoted to clinical duties). A total of 361 responses, representing 22 specialties, were included in the final analysis (Table 1). The mean age of respondents was $37.6(\mathrm{SD} \pm 12.0)$. The largest proportion of responses came from Family Medicine (25\%), Internal Medicine (20\%), Emergency Medicine (10\%), and Anesthesia (8\%).

\section{Awareness of the Campaign and its Recommendations}

A total of 316 respondents (88\%) were aware of the CWC campaign (Table 2). Respondents reported awareness via word of mouth (26\%), medical publications (21\%), conferences (16\%), and hospital communications (10\%). Of these, 185 (59\%) reported 
Table 1. Demographics of Survey Respondents

\begin{tabular}{|c|c|}
\hline Demographic & $n(\%)$ \\
\hline \multicolumn{2}{|l|}{ Gender } \\
\hline Male & $192(53 \%)$ \\
\hline Female & $169(47 \%)$ \\
\hline \multicolumn{2}{|l|}{ Level of training } \\
\hline Resident & $206(57 \%)$ \\
\hline Staff physician & $155(43 \%)$ \\
\hline \multicolumn{2}{|l|}{ Years in practice (if staff physician) } \\
\hline Less than 5 & $15(10 \%)$ \\
\hline $5-10$ & $31(20 \%)$ \\
\hline $10-20$ & $55(35 \%)$ \\
\hline Greater than 20 & $54(35 \%)$ \\
\hline \multicolumn{2}{|l|}{ Primary practice setting } \\
\hline Inpatient (academic) & $181(50 \%)$ \\
\hline Inpatient (non-academic) & $7(2 \%)$ \\
\hline Outpatient (hospital) & $30(8 \%)$ \\
\hline Outpatient (clinic) & $111(31 \%)$ \\
\hline Emergency department & $32(9 \%)$ \\
\hline
\end{tabular}

awareness of their own specialty's recommendations. Only 56 respondents (30.1\%, 95\% CI 23.5-36.7\%) were able to correctly identify $\geq 3$ of these recommendations. Respondents correctly identified an average of 1.6 (95\% CI 1.4-1.9) recommendations (1.7, 95\% CI $1.3-2.1$ vs. $1.5,95 \%$ CI $1.2-1.8$, for faculty physicians versus residents, respectively). The frequency of specific recommendations correctly identified by respondents is presented in Table 2.

\section{Perspectives on Specific CWC Recommendations}

Respondents were presented with the specific CWC recommendations targeted to their specialty, and asked to respond to the recommendations' influence on their practice (Table 3). Respondents noted that the individual recommendations were likely to change their practice in $18.5 \%$ of cases. In only $10.6 \%$ of cases did the respondent note that the recommendation would not change their practice. The remaining $70.9 \%$ of cases stated that the recommendation was already their practice prior to release of the $\mathrm{CWC}$ recommendations.

\section{Views on Low-Value Medical Services}

Respondent attitudes and perspectives on low-value medical services are presented in Figure 1. A majority of respondents either agreed or strongly agreed that they have a responsibility to decrease use of inappropriate health care services (95\%, 95\% CI 93-97\%), and that many patients would benefit
Table 2. Awareness of the Choosing Wisely Canada Campaign

\begin{tabular}{|c|c|}
\hline & $n(\%)$ \\
\hline $\begin{array}{l}\text { "Have you previously heard of the Choosing } \\
\text { Wisely Canada campaign?" }\end{array}$ & $n=361$ \\
\hline Yes & $316(88 \%)$ \\
\hline No & $45(12 \%)$ \\
\hline $\begin{array}{l}\text { "Are you aware of the Choosing Wisely Canada } \\
\text { recommendations targeted to your specialty?" }\end{array}$ & $n=316$ \\
\hline Yes & $186(59 \%)$ \\
\hline No & $130(41 \%)$ \\
\hline $\begin{array}{l}\text { Number of specific recommendations respondents } \\
\text { correctly identified }\end{array}$ & $n=186$ \\
\hline 0 & 71 (38.2\%) \\
\hline 1 & 36 (19.4\%) \\
\hline 2 & $21(11.3 \%)$ \\
\hline 3 & $21(11.3 \%)$ \\
\hline 4 & $15(8.1 \%)$ \\
\hline 5 & $20(10.8 \%)$ \\
\hline & $\begin{array}{l}\text { Proportion } \\
(95 \% \mathrm{Cl})\end{array}$ \\
\hline $\begin{array}{l}\text { Proportion of respondents who correctly identified } \\
\geq 3 \text { recommendations }\end{array}$ & $\begin{array}{c}30.1 \% \\
(23.5-36.7 \%)\end{array}$ \\
\hline
\end{tabular}

Table 3. Perspectives on Specific Choosing Wisely Canada Recommendations

\begin{tabular}{|l|l|}
\hline Yes, this recommendation is likely to change my practice & $449(18.5 \%)$ \\
\hline No, this recommendation will not change my practice & $256(10.6 \%)$ \\
\hline $\begin{array}{l}\text { No, this was already my practice prior to release of the } \\
\text { Choosing Wisely Canada recommendations }\end{array}$ & $1720(70.9 \%)$ \\
\hline
\end{tabular}

from implementation of recommendations to decrease use of these services (82\%, 95\% CI 78-86\%). Respondents mostly disagreed or strongly disagreed with the notion that patients have sufficient information to make informed decisions about inappropriate use of services (54\%, 95\% CI 49-59\%). Most respondents either agreed or strongly agreed that cost to society is an important factor in decision-making around interventions (65\%, 95\% CI 60-70\%), though many disagreed or strongly disagreed that they were aware of the costs of these tests and/ or treatments (30\%, 95\% CI $25-35 \%)$.

Respondents were additionally asked to rank four barriers to implementing recommendations to decrease use of inappropriate services (Figure 2). Most respondents (38\%, 95\% CI 33-43\%) ranked concern regarding medico-legal risk as the number one barrier, with patient requests for tests and treatments closely following (33\%, 95\% CI 28-38\%). Lack of time to assess whether an individual would or would not benefit from a service was 


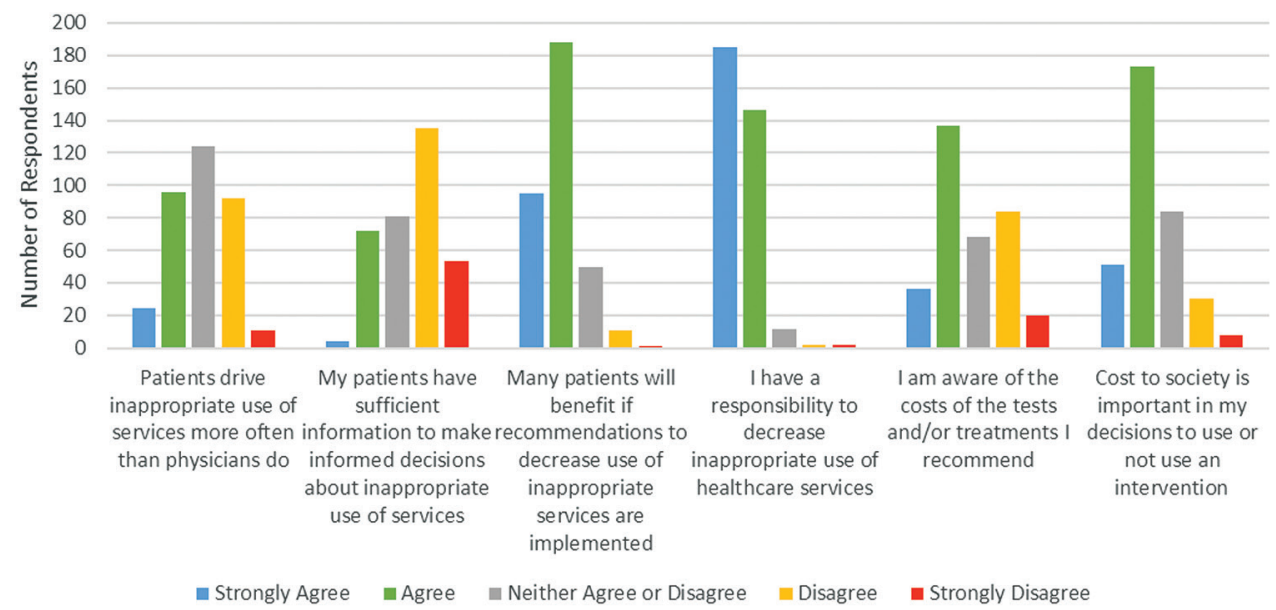

Figure 1. Views on low-value medical services $(n=347)$

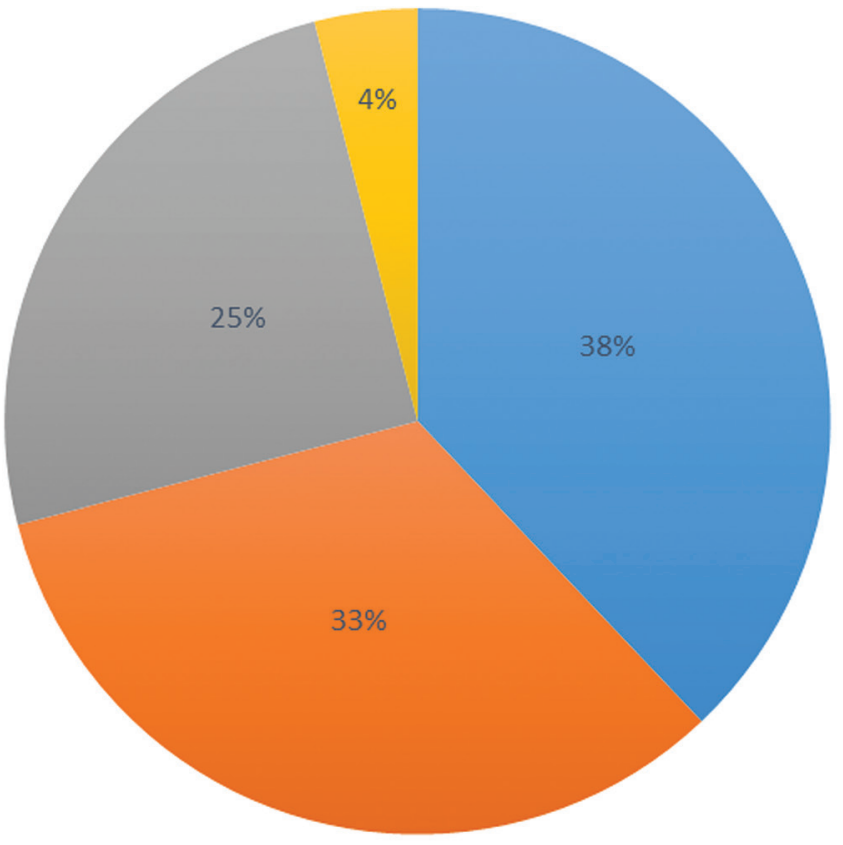

- Concern regarding medico-legal risk

- Patient requests for tests and treatment

घ Lack of time to assess whether patient would benefit $\square$ Payment policies that reward ordering

Figure 2. Barriers to implementing recommendations $(n=347)$.

ranked first by $25 \%$ (95\% CI 20-30\%) of respondents. Only $4 \%$ (95\% CI 2-6\%) of respondents ranked payment policies that reward ordering more services as the top barrier.

\section{Discussion}

As far as we are aware, this is the first survey to assess physician awareness of the CWC campaign. Our results indicate that while most physicians have a general awareness of the campaign, few are able to describe most of the specific recommendations targeted to their own specialty. Only $30.1 \%$ of respondents could appropriately describe three or more recommendations, and over half of respondents were able to describe only one, or couldn't describe any, of the recommendations. In addition, respondents' views were largely supportive of reducing low-value medical care, with physicians acknowledging both responsibility and a patient-benefit to reducing use of inappropriate services.

Our results suggest, however, several possible barriers to the campaign having an impact on practice. For one, the lack of awareness may indicate that there has been inadequate communication of specific recommendations. Previous work in the United States has found that physicians aware of the Choosing Wisely campaign view it as a legitimate source of 
guidance, and report that it has empowered them to reduce the use of unnecessary tests and procedures. ${ }^{10}$ Accordingly, a lack of awareness would likely be a significant impediment in attempts to reduce resource utilization of low-value medical care. However, our findings additionally demonstrate that respondents report practicing in compliance with $70.9 \%$ of recommendations prior to release of the CWC campaign.

While it is possible that there is a discrepancy between physicians' reported and actual practice, these findings are in keeping with other studies suggesting that certain recommendations had high rates of baseline adherence prior to publication of the campaign. A study from the United States identified very low baseline rates of preoperative stress testing before low-risk surgeries, ${ }^{11}$ while another identified infrequent rates of Pap testing among women under 21 years of age and sinusitis imaging for acute mild-to-moderate sinusitis or uncomplicated acute rhinitis. ${ }^{9}$ These findings were all in accordance with published Choosing Wisely recommendations, suggesting that some recommendations were not targeting high-yield areas of lowvalue care. However, while a recent Canadian study by Kirkham and colleagues assessing preoperative testing prior to low-risk surgical procedures within Ontario hospitals demonstrated low baseline utilization of certain tests (e.g., echocardiography, stress tests), it did show widely variable utilization of other tests (e.g., electrocardiogram) among institutions. ${ }^{12}$ This may indicate that further communication of the CWC recommendations may have greater impact within institutions with lower rates of baseline compliance. Additionally, measurements of baseline utilization prior to release of further recommendations may help identify areas of greatest potential impact.

Our study additionally demonstrated other areas in which further interventions could potentially impact rates of utilization of low-value care. Many of our respondents believed that patients drive inappropriate services more often than physicians, but that patients largely lack the information to make these informed decisions. Strengthening communication of the campaign to the general public, while targeting specific high-yield areas of patient utilization, may help further reduce use of certain services. Furthermore, though a majority of respondents identified cost to society as an important factor in the decision to use or not use an intervention, less than half of respondents reported awareness of the cost of tests and treatments they prescribe. Numerous other studies have found deficits in both self-reported and actual awareness of the costs of medical care in the US. ${ }^{10,13}$ Surveys of Canadian physicians have demonstrated very poor cost awareness among both family physicians and residents. ${ }^{14,15}$ While enhancing knowledge of low-value areas of care is the primary goal of campaigns such as CWC, it is possible that physician education on the costs of tests and treatments would lead to further improvements in resource utilization. Finally, evidence suggests that physicians who value cost consciousness are more likely to avoid the use of low-value services, while greater knowledge of guidelines alone is not associated with reduced use of low-value services. ${ }^{16}$ Accordingly, efforts may be further focused on enhancing a sense of cost consciousness among trainees and physicians.

\section{Limitations}

Our survey does possess several limitations. Firstly, our response rate was only $33 \%$; thus, it remains possible that our sample was not fully representative of the target population, and we cannot rule out a selection bias favouring respondents more familiar with the CWC campaign. Secondly, we restricted our population to physicians associated with McMaster University. We cannot extrapolate these findings to physicians associated with other universities or physicians in non-academic settings, especially given the fact that local CWC communication initiatives have been occurring to variable extents across the country. Thirdly, we were unable to avoid the possibility that respondents were able to search for their specialty-specific recommendations while completing the survey. However, we have no reason to believe respondents would have any incentive to do so. Lastly, we were unable to account for physicians who identify with more than one medical specialty.

\section{Conclusions}

Despite general awareness of the CWC campaign, most physicians cannot describe recommendations targeted to their own specialty. Nonetheless, many of these physicians report already practicing in compliance with these recommendations. Multiple barriers to implementing change were identified, including the potential of recommendations targeting lower-yield areas of care, patient requests for tests and treatment, physician awareness of cost, and concern regarding medico-legal risk. Future studies are required to explore awareness of the campaign in other academic and community sites across the country. Additionally, future efforts should be directed towards identifying methods of improving communication of current CWC recommendations, including the potential for targeting both specific recommendations and institutions with low baseline compliance, and to determine areas of care that would most benefit from additional recommendations.

\section{References}

1. Levinson W, Huynh T. Engaging physicians and patients in conversations about unnecessary tests and procedures: Choosing Wisely Canada. CMAJ 2014;186(5):325-6.

2. Cassel CK, Guest JA. Choosing Wisely: Helping physicians and patients make smart decisions about their care. J Am Med Assoc 2012;307(17):1801-2.

3. Brody H. Medicine's ethical responsibility for health care form -- the top five list. NEJM 2010;362:283-85. 


\section{CSIM Mission Statement}

\section{Mission Statement}

The CSIM is a non-profit professional society that promotes the health and well being of Canadian patients, their communities, and their health care systems. We seek to foster leadership and excellence in the practice of General Internal Medicine (GIM) through research, education, and advocacy for health promotion and disease management.

$$
\text { 2015;24(2):167-74. }
$$
"Choosing Wisely": a growing international campaign. BMJ Qual Saf

5. Yong PL, Saunders RS, Olsen L. The healthcare imperative: Lowering costs and improving outcomes. Institute of Medicine (US) Roundtable on Evidence-Based Medicine. Washington, DC: National Academies Press (US); 2010.

6. The ABIM Foundation. Unnecessary tests and procedures in the health care system [Internet]. 2016. Available at: http://www.choosingwisely.org/wpcontent/uploads/2015/04/Final-Choosing-Wisely-Survey-Report.pdf.

7. Vogel L. More hospitals Choosing Wisely. CMAJ 2015;187(10):722-22.

8. Lakhani A, Lass E, Silverstein WK, Born KB, Levinson W, Wong BM. Choosing Wisely for medical education : Six things medical students and trainees should question. Acad Med 2016;91(10):1374-78.

9. Rosenberg A, Agiro A, Gottlieb M, Barron J, Brady P, Liu Y, et al. Early trends among seven recommendations from the Choosing Wisely campaign. JAMA Intern Med 2015;175(12):1913-20.

10. Colla CH, Kinsella EA, Morden NE, Meyers DJ, Rosenthal MB, Sequist TD. Physician perceptions of Choosing Wisely and drivers of overuse. Am J Manag Care 2016;22(5):337-43.

11. Kerr EA, Chen J, Sussman JB, Klamerus ML, Nallamothy BK. Stress testing before low-risksSurgery: So many recommendations, so little overuse. JAMA Intern Med 2015;175(4):645-7.

12. Kirkham KR, Wijeysundera DN, Pendrith C, et al. Preoperative testing before low-risk surgical procedures. CMAJ 2015;187(11):349-58.

13. Broadwater-Hollifield C, Gren LH, Porucznik CA, Youngquist ST, Sundwall DN, Madsen TE. Emergency physician knowledge of reimbursement rates associated with emergency medical care. Am J Emerg Med 2014;32(6):498-506.

14. Allan GM, Innes G. Family practice residents' awareness of medical care costs in British Columbia. Fam Med 2002;34(2):104-9.

15. Allan GM, Innes GD. Do family physicians know the costs of medical care? Survey in British Columbia. Can Fam Physician 2004;50:263-70.

16. Grover M, Abraham N, Chang YH, Tilburt J. Physician cost consciousness and use of low-value clinical services. J Am Board Fam Med 2016;29(6):785-92.

\section{Vision}

We believe that General Internal Medicine in Canada plays a central role in the training of current and future clinicians, in clinical research, in patient care, in health promotion, and in health advocacy; and that it unites a body of knowledge, values, and principles of care that lay the foundation for excellence in the Canadian health care system.

\section{Values}

We embrace the ethical and professional standards that are common to all healing professions, as well as the specific values of generalism, teamwork, competency-based training, life-long learning, evidence-based medicine, holism, and humane, patient-centered care.

\section{Mission}

La Société canadienne de médecine interne (SCMI) est une association professionnelle sans but lucratif qui entend promouvoir la santé et le bienêtre des patients, des collectivités et des systèmes de santé canadiens. Elle souhaite également promouvoir le leadership et l'excellence dans l'exercice de la médecine interne générale en favorisant la recherche, léducation, la promotion de la santé et la gestion des soins thérapeutiques.

\section{Vision}

La Société a l'intime conviction que la médecine interne générale occupe une place centrale dans la formation des cliniciens aujourd'hui et à l'avenir, dans la recherche clinique, dans la prestation des soins et des services de santé et dans la promotion de la santé, et que la discipline se fonde sur un savoir, des valeurs et des principes thérapeutiques essentiels à la poursuite de l'excellence dans le système de santé canadien.

\section{Valeurs}

La Société fait sienne les normes éthiques et professionnelles communes aux professions de la santé ainsi que les valeurs particulières du généralisme, du travail déquipe, de la formation axée sur les compétences, de léducation permanente, de la médecine factuelle, de l'holisme et des soins et des services de santé humains, centrés sur le patient.

\section{CSIM Continuing Professional Development Mission Statement}

Our ultimate goal is to go beyond the simple transmission of information. Our goal is to make a lasting impact on the knowledge, skills and attitudes of clinicians and future clinicians; to narrow the theory to practice gap; to improve the health of our patients and of all Canadians.

\section{Mission de la SCMI sur le plan du développement professionnel continu}

Notre but ultime déborde du cadre de la simple transmission d'information. Il consiste à produire un effet durable sur le savoir, les compétences et les attitudes du médecin, à combler lécart qui sépare la théorie de la pratique, à améliorer la santé de nos patients et de tous les canadiens. 